\title{
A SECOND PARASITIC CREMATOGASTER
}

\author{
By William MoRton Wheeler
}

\section{Harvard University}

In $1930 \mathrm{I}$ described in this journal a diminutive, presumably parasitic, female ant, Crematogaster (Acrocoelia) kennedyi, taken by Professor C. H. Kennedy in Indiana from a colony of our common acrobat ant, C. lineolata Say. Now Dr. W. S. Creighton has sent me winged females of another closely related form which he collected recently at Roanoke, Virginia, in a colony of C. pilosa Pergande. Since the colony also contained many females of the host, the alternatives discussed in my previous paper, seem to be applicable to this case. We may suppose that we are dealing either with a workerless parasite or with a remarkable dimorphism and dichromatism of the females of lineolata and pilosa. The latter supposition seems to be improbable because the occurrence of two forms of females cannot be a normal peculiarity of lineolata, since in hundreds of colonies of this ant examined by myself and others during the past 40 years only females of the large type have been encountered. And though smaller females occasionally occur in colonies of certain tropical species of Crematogaster, they are always few in number, wingless and ergatomorphic, and therefore quite unlike the perfect, winged microgynes taken by Prof. Kennedy and Dr. Creighton. Nevertheless, a rather serious objection to the interpretation of these insects is the presence of virgin females of the host species in the same nest. This has never been observed in any of the numerous recorded cases of ant parasitism. In the European Strongylognathus testaceus, however, the mother queen of the host colony (Tetramorium cæspitum) is not eliminated after the intrusion of the parasitic female, and Wasmann described a flourishing mixed colony of these ants in which a few male pupæ of the host species 
were present. Perhaps, therefore, C. kennedyi and creightoni represent a hitherto unknown type of social parasitism, in which the males and females of the parasite are permitted to develop to maturity in a host colony which not only retains its mother queen but also succeeds in rearing females and males of its own species. That the two parasitic species of Crematogaster have been brought to light only very recently is not surprising, because all the workerless parasitic ants are extremely rare. One of these, Epœcus pergandei Emery, described in 1894, from specimens taken by Pergande near Washington, D. C., is still known only from the types, notwithstanding long and diligent search for additional specimens by Dr. W. M. Mann, Dr. Creighton and myself. Moreover, the presence of workerless parasites in a colony is very apt to be overlooked unless the nest happens to be examined during the few days that intervene between the emergence of the parasites and their nuptial or dissemination flight. Since there is every reason to believe that both kennedyi and creightoni are derived phylogenetically from their respective host species, either by mutation or, more probably, by a gradual reduction in size and fecundity of certain females (compare, for example, the series of temporary social parasites of the genus Formica, beginning with such forms as $F$. rufa and truncorum and ending in the North American species of the microgyna group), the parasitism of the two species of Crematogaster may be in a primitive phylogenetic stage, that is one in which the reduction in size and fecundity of the female is already accomplished but in which the host species has not yet acquired the habit of substituting the parasitic queen for that of its own species, as in certain other workerless species (Anergates, Bruchomyrma, etc.).

Crematogaster (Acrocolia) pilosa, the host of C. creightoni is not as well known as many of the other members of the lineolata "Formenkreis," which has a wide distribution, embracing Nova Scotia, Southern Ontario and the whole United States. Emery (1849) described only the worker pilosa as a subspecies of lineolata from specimens furnished by Pergande, who discovered it in the District of Columbia. It has since been recorded from Southern New Jersey and Florida. The specimens collected by Dr. 
Creighton comprise three workers, three females and a male.

The worker closely resembles the typical lineolata in form and sculpture, but the head is smoother and more shining posteriorly and the epinotal spines, though fully as long as in lineolata, are distinctly more slender and tapering and even more acute at their tips. The pilosity is conspicuously longer and more abundant on all parts of the body, and, on the antennal scapes and legs, long and suberect, whereas in lineolata and its varieties these parts have only a dilute and appressed pubescence, though of somewhat variable length in specimens from different localities. Color brown or brownish red, with the head somewhat darker and the gaster piceous or blackish; mandibles sometimes yellowish and paler than the head; funiculi, except their tips, usually paler than the scapes.

The female (undescribed) measures $8.5-9 \mathrm{~mm}$. and is of the same size and deep piceous or blackish coloration as the typical lineolata, but the wings have their basal two-thirds distinctly tinged with brown and the veins and pterostigma are dark brown, instead of white as in lineolata. Pilosity like that of the worker, much more abundant and conspicuous on all parts of the body, long and suberect on the antennal scapes and tibiæ. Even the wing-membranes are distinctly more pubescent than in the female lineolata. Anterior two-thirds of head more shining, more sharply and more coarsely rugulose, with less distinct punctulation or reticulation between the rugæ.

In the absence of authentic males of pilosa I am unable to decide whether the single male sent me by Dr. Creighton belongs to the host or to the parasitic species. Its very small size (only $3 \mathrm{~mm}$.) might indicate that it belongs to the latter. Though the head and thorax are almost hairless, the pilosity of the legs is like that of the pilosa worker. The mandibles are narrower than in the male of the typical lineolata and have only 2 instead of 3 or 4 teeth. The color of the body is deep black, with brown legs and antennal funiculi and more reddish scapes and mandibles. The wings are distinctly yellowish at the base, with brown veins and pterostigma, and therefore resemble the wings of the female pilosa. 
Crematogaster (Acrocelia) creightoni sp. nov.

Female. Length 5 - $5.2 \mathrm{~mm}$.; fore wing $4 \mathrm{~mm}$.

Closely resembling kennedyi Wheeler in form but averaging smaller; the head narrower in proportion to its length, with somewhat more rounded sides; antennal scapes slightly longer. Thorax shorter; mesonotum decidely shorter, scarcely longer than broad; epinotal spines longer, more slender, less swollen at their bases. Petiole more concave above, with more sharply marginate sides; postpetiole distinctly shorter in proportion to its width and with less pronounced posterior emargination. Gaster of the same shape as in kennedyi.

Head more shining, especially behind; fine piligerous punctures of mesonotum and scutellum more numerous.

Pilosity on all parts of the body, including the wingmembranes, longer, much more abundant and of more uneven length.

Brownish red; front and middle of occiput, mesonotum, scutellum and gaster black; scapes, upper surface of postpetiole and middle portions of femora and tibiæ dark brown; pleuræ spotted with brown. Wings, as in kennedyi, white with white veins and white, or in some specimens, slightly brownish pterostigma.

Described from six specimens from Roanoke, Virginia, Sept. 10, 1932 (W. S. Creighton).

C. creightoni might, perhaps, be regarded as a subspecies of kennedyi. In color and pilosity the female of the former is certainly more closely related to its host, but the color of the wings is quite different, being like that of kennedyi and the typical lineolata. Dr. Creighton has sent me the following note: "Unfortunately, I cannot give you any startling facts about the colony since it appeared to be perfectly normal in every respect. As I recall, it was under a limestone slab not far from a small stream. There were many sexual forms in the nest, and of these I should say that the normal ones exceeded the parasitic males and females by perhaps two to one. Certainly there was no excessive proportion of the latter." 

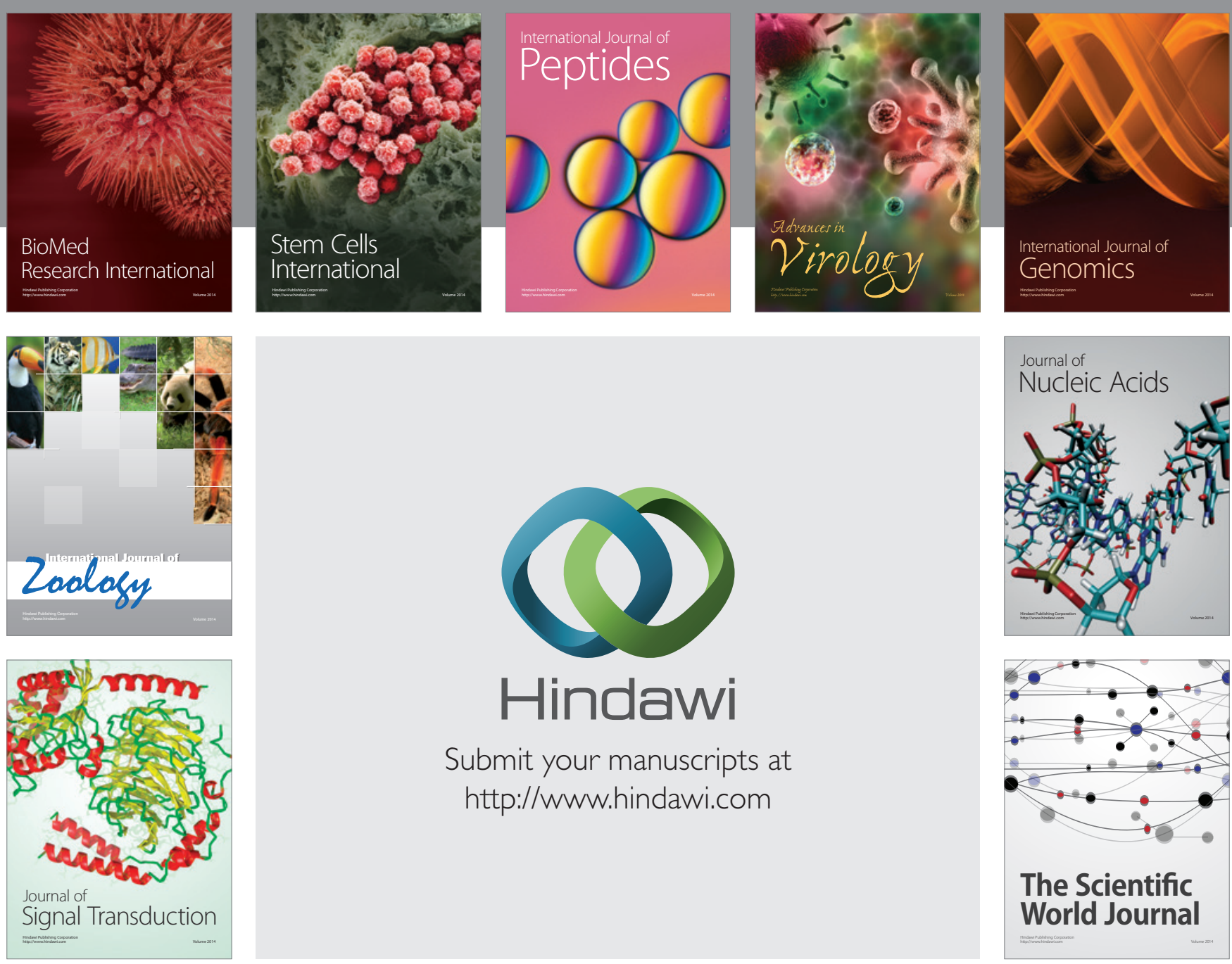

Submit your manuscripts at

http://www.hindawi.com
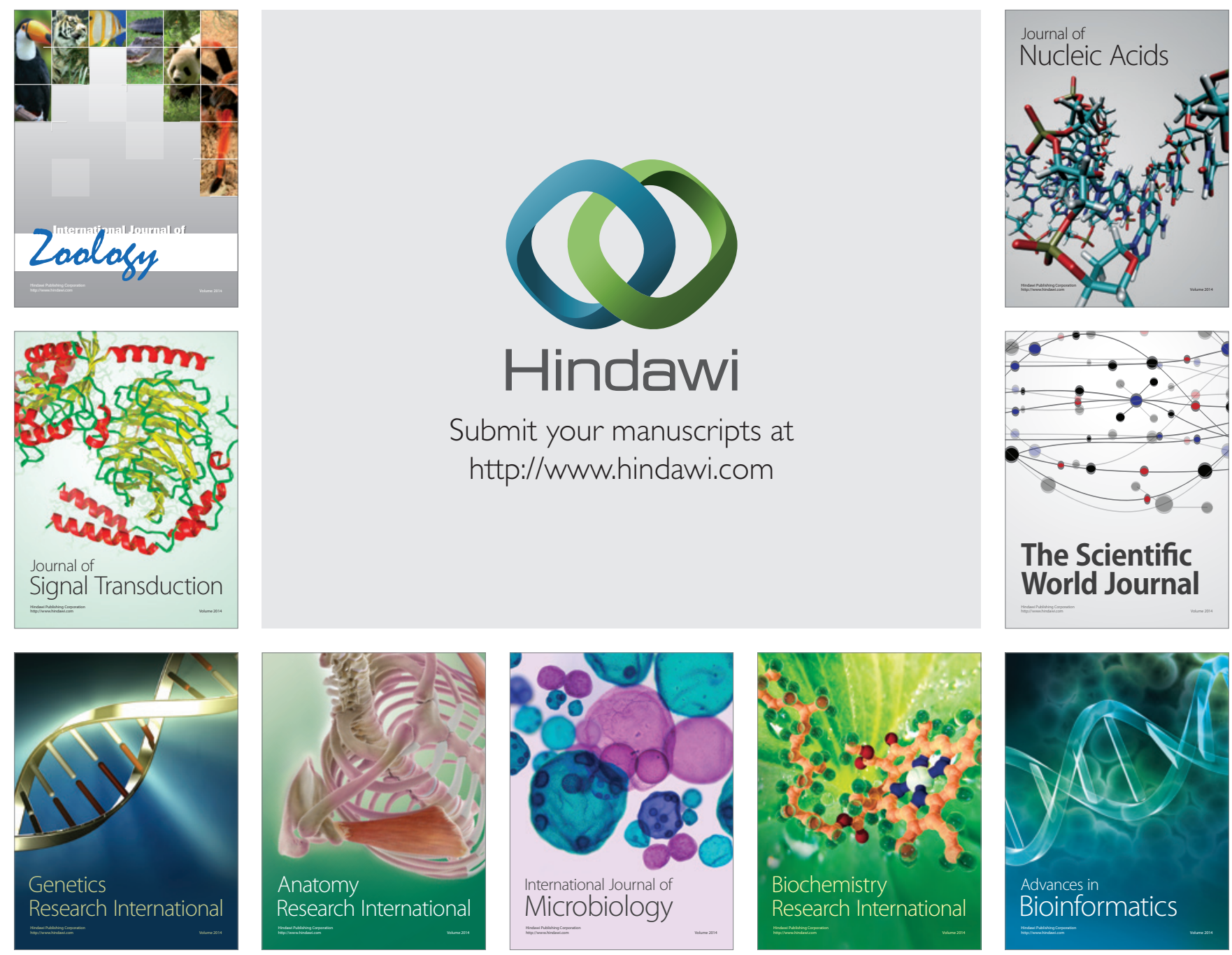

The Scientific World Journal
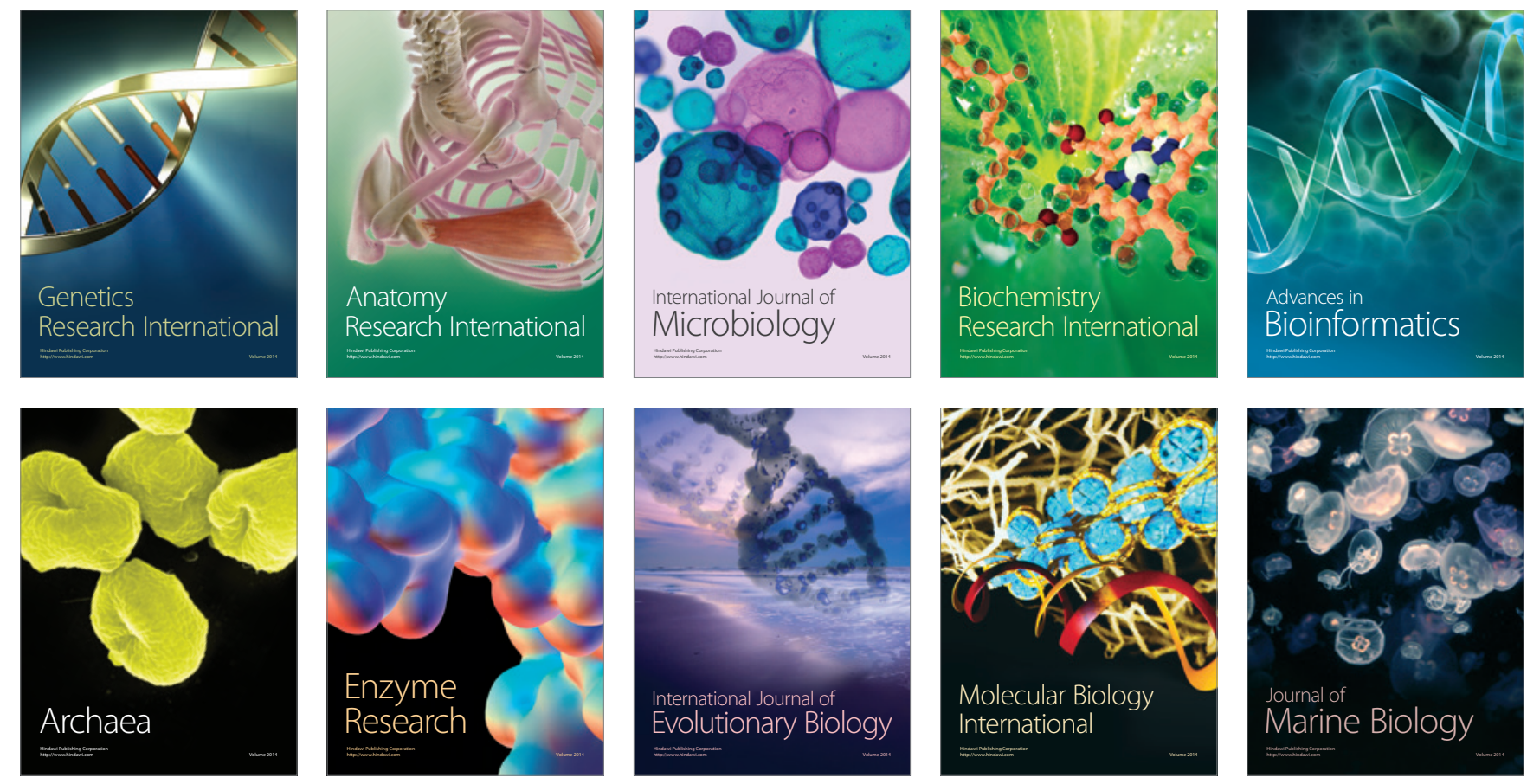